\title{
Does Emergency Severity Index Predict Acuity Among Traumatic Brain Injury Patients?
}

\author{
Zohre Najafi' (D) Hossein Zakeri² (D), Abbas Abbaszadeh $^{3}$ (D), Mohsen Ebrahimi ${ }^{4}$ (D) Amir Mirhaghi ${ }^{5}$ (D) \\ 'Department of Nursing, School of Nursing and Midwifery, Shahid Beheshti University of Medical Sciences, Tehran, Iran \\ 2Department of Emergency Medicine, Faculty of Medicine, Mashhad University of Medical Sciences, Mashhad, Iran \\ ${ }^{3}$ Department of Medical Surgical Nursing, School of Nursing and Midwifery, Shahid Beheshti University of Medical Sciences, Tehran, Iran \\ ${ }^{4}$ Department of Emergency Medicine, Faculty of Medicine, Mashhad University of Medical Sciences, Mashhad, Iran \\ ${ }^{5}$ Nursing and Midwifery Care Research Center, Mashhad University of Medical Sciences, Mashhad, Iran
}

Cite this article as: Najafi Z, Zakeri $\mathrm{H}$, Abbaszadeh A, Ebrahimi M, Mirhaghi A. Does Emergency Severity index predict acuity among traumatic brain injury patients? Eurasian J Emerg Med. 2018; 17 (3): 103-8.

\begin{abstract}
Aim: It is unclear whether emergency severity index (ESI) is valid to triage patients with trauma. We aimed to determine the accuracy of ESI in both prehospital and hospital settings.

Materials and Methods: This study was an observational prospective cohort where in patients with traumatic brain injury (TBI) were followed from the accident scene to the hospital. Used resources and timing indices were collected both on the scene as well as at the hospital. A logistic regression was performed to ascertain the effects of clinical parameters on the likelihood of survival of patients with TBI regarding 24 hour mortality.

Results: A total of 185 patients were included in this study. The mortality rate was $14 \%(25 / 185)$. The logistic regression model was statistically significant at $\mathrm{X} 2=57.8, \mathrm{p}=0.001$. An enter logistic regression analysis showed that used resources either in prehospital or in hospital significantly improved predictions related to mortality. The model explained the $49 \%$ variance in survival of patients with TBI.

Conclusion: The ESI-used resources can be used to triage patients with TBI for pre-hospital and hospital emergency care. It is recommended that ESI triage tool be used to triage patients with TBI.
\end{abstract}

Keywords: Traumatic brain injury, emergency severity index, triage, prehospital emergency

\section{Introduction}

Trauma is the main cause of morbidity and mortality in people aged $<40$ years, and is the third most common cause of death worldwide. It is responsible for 5 million deaths annually (1-3). Time is considered an essential determinant for the outcome of patients with trauma (4). A fundamental tenet of trauma care is the "golden hour." It is the immediate time after injury when resuscitation, stabilization, and rapid transport are perceived to be most beneficial for the patient $(5,6)$. The basic principle of caring for patients with trauma is to provide timely care. Prehospital prompt response, resuscitation, immobilization, and rapid transfer of patient to trauma centers are very important factors in the trauma management system $(7,8)$. It has been shown that providing definitive care earlier at trauma centers decreases mortality $(9,10)$. Although prompt response is common in developed countries, it is unclear whether response time is plausible in developing countries, and what its effects on mortality are (11). Any delay in management of progressive hemorrhagic injury is a significant cause of morbidity and mortality in the emergency department (ED). A computed tomography (CT) scan reliably predicts progressive hemorrhagic injury in patients with trauma; therefore, time to CT scan (12) as well as other tests such as hematocrit (HCT), which is a significant independent predictor of mortality in patients

ORCID IDs of all authors: Z.N. 0000-0002-1848-8169; H.Z. 0000-0001-7965-9657; A.A. 0000-0001-5708-7838; M.E. 0000-0003-2168-8476; A.M. 0000-0002-4482-1156. 
with trauma (13-15), must be monitored rigorously. Therefore, it can be concluded that timing indices have a great impact on management of patients with trauma. Literature shows that little empirical knowledge exists about the exact influence of prehospital time, hospital time, radiological and laboratory testing time, and time to therapeutic interventions on outcome of patient with trauma. In addition, because traumatic injuries are increasingly recognized as a leading source of morbidity and mortality in developing countries, context-specific research is necessary to identify opportunities for the prevention and improved treatment.

Triage systems are also important tools for reducing time to definite care $(16,17)$. Although emergency severity index (ESI) is practiced worldwide, little data exist about its use in trauma centers. ESI uses patient acuity (stability of vital signs and degree of distress) as well as expected used resource to assign five triage levels from level 1 (most urgent) to level 5 (least urgent) (18). As compared to other triage systems, estimating expected resource in the triage assignment is a unique feature of ESI. The nurses in ED need to clearly understand that the estimate of resources is related to the standards of care. Resources can be diagnostic services such as tests, procedures, consults, or therapeutic interventions. However, validity and reliability of ESI have been well documented in the literature. It is unclear whether used resource rating system of ESI predicts acuity in patients with trauma. Therefore, we aimed to determine the description of the timing and preventive care measures in prehospital and hospital settings with the mortality of the patients with trauma and validity of used resource rating system of ESI among patients with traumatic brain injury (TBI).

\section{Materials and Methods}

This study was an observational prospective cohort that followed patients with TBI from the accident scene to the hospital between February and September 2016.

Data collection was performed after receiving approval from the ethics committee at Mashhad University School of Medicine (No. 940948). The study is granted exemption from ethics committee, so informed consent is not required because the study involves no more than minimal risk to the subjects.

\section{Setting}

This study was conducted in the Hasheminezhad Hospital in Mashhad, Razavi Khorasan, Iran, which is the second largest Level 1 trauma center (320 beds) in the city. The hospital provides several specialties, including neurosurgical, emergency medicine, orthopedic, surgical, and internal medicine services, 24 hours per day. Annually, the hospital ED receives 14,500 patients with trauma, most of whom arrive by ambulance. All nurses in the ED have both a Bachelor of Science (B.S.) in nursing and Trauma Certified Registered Nurse certification. All emergency physicians in the ED are specialists in emergency medicine. Emergency medical services (EMS) are provided by professional individuals who are trained to provide basic trauma life support, such as immobilization, airway management, and intravenous fluid therapy, during ambulance transfers. All paramedics must have a B.S. in EMS. They transfer patients with trauma from the scene to the EDs in the shortest possible time with the aim of reducing morbidity as well as mortality.

\section{Data collection}

The patients with TBI who were received by ambulance and admitted to the ED were assessed. Patient records were used to collect relevant data, including age, gender, mechanism of injury, and medical history. Prehospital transfer time and hospital timing measures and used resources were recorded.

Prehospital transfer time included time taken to reach scene and transfer time from scene to hospital. Hospital time included time taken to emergency physician visit and neurosurgeon specialist visit, as well as time taken to perform imaging studies (X-ray, CT scan, and sonography), laboratory examination (hemoglobin, HCT), and intubation. Used resources in prehospital and hospital settings were calculated based on ESI method and conventional method. For example; if a patient receives a chest X-ray and a sonography in ED, she/ he would receive score 1 in ESI method and score 2 in conventional method. All imaging studies are considered score 1 in ESI method apart from the numbers of resources. In other hand, each imaging study scores 1 in conventional method and 2 in the above example. In fact, each intervention was scored one in conventional method.

To assess in-hospital mortality, we examined death rates in the first 24 hours post-injury. All included patients were followed up for mortality over 24 hours in ED. Therefore, based on their outcome (dead or alive) in the first 24 hours post-injury, patients with TBI were divided into two groups.

\section{Patient selection}

During the study period, patients with TBI who met the following criteria were included in the study: the mechanism of injury (MOI) was a traffic accident, they were transported directly from the scene by an EMS ambulance, they had an injury severity score (ISS >9), they were aged more than 18 years but less than 85 years, and they had at least one vital sign parameter higher than zero at the scene (to include only cases without clinical death). Exclusion criteria included incomplete data in either the pre-hospital or hospital patient records (i.e., vital signs and parameters), pregnancy, comorbidities (diabetes, cardiovascular disease, and chronic obstructive pulmonary disease), and transfer time from the scene to the hospital of more than $60 \mathrm{~min}$ and transfer of patients to other health-care centers in the first 24 hours.

Variables: Used resources and time periods were assessed in prehospital and hospital settings.

\section{Used resources based on emergency severity index (ESI Ver.4)}

ESI is a five-level triage algorithm that categorizes patients by evaluating both patient acuity and resource needs. To sort patients into one of the five triage levels, the ESI algorithm uses four decision points $(A, B, C$, and $D)$. At decision point $C$, the nurse assigns ESI levels 3-5 by assessing both acuity and predicted resource needs. Acuity level is assessed by the triage nurse. If a patient does not meet high acuity level criteria (ESI level 1 or 2 ), the triage nurse evaluating expected resources needs to help determine a triage level (ESI level 3, 4, or 5). Resources can be hospital services, tests, procedures, consults, or interventions in $\mathrm{ESI}(18,19)$. The nurse then predicts the number of resources a patient will need to reach a disposition. It is important to note that resource prediction is only used for less acute patients (level 3, 4, or 5). ESI levels 3, 4, and 5 are differentiated by the nurse's de- 
termination of how many different resources are needed to make a patient disposition (20). On the basis of the triage nurse's predictions, patients who are expected to consume no resources are classified as ESI level 5, those who are likely to require one resource as ESI level 4, and those who are expected to need two or more resources as ESI level 3. Patients who need two or more resources have been shown to have higher rates of hospital admission and mortality, and longer lengths of stay in the ED (21).

\section{Used resources based on the conventional method}

Used resources were also calculated based on the conventional method. Each intervention was valued one in the conventional method. For example, simple dressing or splint scored one. In the conventional method, patient with two graphies receives two scores, whereas they receive one score based on the ESI method. All used resources were summed up for each patient.

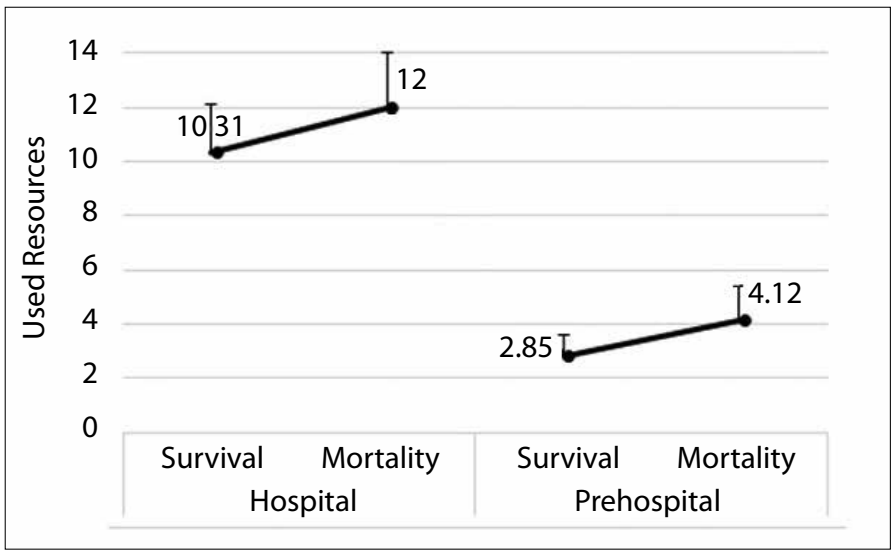

Figure 1. Frequency of used resources in pre-hospital and hospital settings based on the emergency severity index method

\section{Prehospital time}

Transfer time is composed of "Time to Scene" and "Scene to Hospital time." Time to scene is defined as the time required for EMS to deploy after emergency call; and scene to hospital time is defined as the time from departing scene to arrival at the hospital.

\section{Hospital time}

Time to hospital resources including emergency physician, specialist, intubation, imaging studies (X-ray, sonography, and CT scan), laboratory exam [hemoglobin $(\mathrm{mg} / \mathrm{dL})$ and $\mathrm{HCT}(\%)$ ] were computed from call to EMS as well as during in-hospital stay. Time period was calculated in minutes.

\section{Confounders analysis}

We considered several potential confounders of the association between acuity of head injury and mortality during the first day of admission. These included $\mathrm{MOI}$, ISS $<9$, and other life-threatening injuries. For analysis, traffic accident survivors (driver, passenger, motorcycle, bicycle, and pedestrian) were included in the study. Other MOls were excluded because they may have coincided with different patterns of injury. Patients with TBI with a minimum ISS score of 9 were included only if that score belonged to a brain injury. TBI is often associated with a high-velocity circumstance; hence, injuries to other parts of the body are common.

\section{Statistical analysis}

Timing measure variables that were normally distributed between the two independent groups were compared using the T-test. Acuity scales for survival probability in patients with TBI, such as the ESI, were calculated based on both prehospital and hospital parameters.

Table 1. Characteristics of patients in both groups

\begin{tabular}{|c|c|c|c|c|c|c|c|}
\hline Characteristics & $\begin{array}{c}\text { All } \\
(n=185)\end{array}$ & $\begin{array}{l}\text { Survival } \\
(n=160)\end{array}$ & $\begin{array}{c}\text { Mortality } \\
(n=25)\end{array}$ & Characteristics & $\underset{(n=185)}{\text { All }}$ & $\begin{array}{l}\text { Survival } \\
(n=160)\end{array}$ & $\begin{array}{l}\text { Mortality } \\
(n=25)\end{array}$ \\
\hline Age years old (mean+SD) & $39.01 \pm 18.4$ & $38.1 \pm 17.7$ & $44.2 \pm 21.9$ & Gender female (n, \%) & $44(24)$ & $37(23.1)$ & $7(28)$ \\
\hline Blunt trauma $(n, \%)$ & $170(92)$ & $147(91.9)$ & $23(92.0)$ & Penetrating trauma $(\mathrm{n}, \%)$ & $15(8)$ & $13(8.1)$ & $2(8.0)$ \\
\hline \multicolumn{8}{|l|}{ Prehospital } \\
\hline $\begin{array}{l}\text { Time to scene (min) } \\
(\text { mean+SD) }\end{array}$ & $15.17 \pm 6.05$ & $15.20 \pm 6.09$ & $15.03 \pm 5.45$ & $\begin{array}{c}\text { Scene to hospital } \\
\text { time (min) (mean+SD) }\end{array}$ & $15.42 \pm 6.15$ & $15.42 \pm 6.21$ & $15.37 \pm 5.45$ \\
\hline Transfer time (min) (mean+SD) & $47.5 \pm 76.3$ & $49.8 \pm 81.7$ & $33.3 \pm 13.3$ & Used resources & $3.02 \pm 0.93$ & $2.85 \pm 0.74$ & $4.12 \pm 1.26$ \\
\hline \multicolumn{8}{|l|}{ Hospital } \\
\hline $\begin{array}{l}\text { Time to physician visit (min) } \\
\text { (mean+SD) }\end{array}$ & $15.47 \pm 6.17$ & $15.48 \pm 6.23$ & $15.40 \pm 5.48$ & $\begin{array}{c}\text { Time to specialist } \\
\text { visit (min) (mean+SD) }\end{array}$ & $\begin{array}{c}15.51 \pm 6.58 \\
n=155\end{array}$ & $15.51 \pm 7.05$ & $15.50 \pm 6.24$ \\
\hline $\begin{array}{l}\text { Time to graphy (min) } \\
\text { (mean+SD) }\end{array}$ & $\begin{array}{c}15.35 \pm 6.51 \\
n=170\end{array}$ & $\begin{array}{c}15.24 \pm 6.54 \\
n=152\end{array}$ & $\begin{array}{c}17.07 \pm 6.22 \\
n=18\end{array}$ & $\begin{array}{c}\text { Time to CT } \\
\text { scan }(\min )(\text { mean+SD) }\end{array}$ & $\begin{array}{c}15.47 \pm 6.48 \\
n=173\end{array}$ & $\begin{array}{c}15.36 \pm 6.50 \\
n=156\end{array}$ & $\begin{array}{c}17.17 \pm 6.26 \\
n=17\end{array}$ \\
\hline $\begin{array}{l}\text { Time to sonography (min) } \\
\text { (mean+SD) }\end{array}$ & $\begin{array}{c}13.15 \pm 7.35 \\
n=62\end{array}$ & $\begin{array}{c}12.47 \pm 7.36 \\
n=56\end{array}$ & $\begin{array}{c}17.36 \pm 6.23 \\
n=6\end{array}$ & $\begin{array}{l}\text { Time to laboratory } \\
\text { exam (min) (mean+SD) }\end{array}$ & $\begin{array}{c}15.21 \pm 7.24 \\
n=175\end{array}$ & $\begin{array}{c}15.17 \pm 7.26 \\
\mathrm{n}=156\end{array}$ & $\begin{array}{c}15.59 \pm 7.14 \\
n=19\end{array}$ \\
\hline $\begin{array}{l}\text { Hemoglobin }(\mathrm{mg} / \mathrm{dL}) \\
(\text { mean+SD) }\end{array}$ & $\begin{array}{c}13.98 \pm 2.70 \\
n=135\end{array}$ & $\begin{array}{c}14.20 \pm 227 \\
n=118\end{array}$ & $\begin{array}{c}12.46 \pm 4.56 \\
n=17\end{array}$ & $\begin{array}{l}\text { Hematocrit (\%) } \\
(\text { mean+SD) }\end{array}$ & $\begin{array}{c}40.62 \pm 6.54 \\
n=136\end{array}$ & $\begin{array}{c}41.33 \pm 4.99 \\
n=118\end{array}$ & $\begin{array}{c}36.00 \pm 11.92 \\
n=18\end{array}$ \\
\hline Used resources & $10.54 \pm 1.91$ & $10.31 \pm 1.79$ & $12.0 \pm 2.04$ & & & & \\
\hline
\end{tabular}


The effect of each predictor on the outcome variable was assessed individually by performing a univariate analysis. Variables showing a statistically significant association at $5 \%$ level of significance in the univariate analysis were included in the multivariate analysis. Multivariate logistic regression was used to develop a prognostic model for the outcome (mortality, no/yes) of the first 24 hour of admission. Models using a pre-defined group of predictor variables (method, "enter") in the univariate analysis as well as multivariate analysis were employed.

Table 2. Univariate analysis of variables in the equation according to the enter method (Ref=Survival)

\begin{tabular}{|l|c|c|c|c|}
\hline & & \multicolumn{2}{|c|}{$95 \%$ CI } & \\
\hline Variable & Odds ratio & Lower & Upper & p \\
\hline ESI method & & & & \\
\hline Used resources in prehospital & 0.261 & 0.152 & 0.448 & 0.000 \\
\hline Used resources in hospital & 0.591 & 0.453 & 0.772 & 0.000 \\
\hline $\begin{array}{l}\text { Total used resources } \\
\text { (Prehospital plus hospital) }\end{array}$ & 0.649 & 0.547 & 0.771 & 0.000 \\
\hline Conventional method & & & & \\
\hline Used resources in prehospital & 0.507 & 0.377 & 0.683 & 0.000 \\
\hline Used resources in paraclinic & 2.756 & 1.677 & 4.527 & 0.000 \\
\hline Used resources in hospital & 0.428 & 0.289 & 0.634 & 0.000 \\
\hline $\begin{array}{l}\text { Used resources in paraclinic } \\
\text { and hospital }\end{array}$ & 0.778 & 0.579 & 1.045 & 0.096 \\
\hline Total used resources & 0.682 & 0.566 & 0.822 & 0.000 \\
\hline
\end{tabular}

In prognostic research, the logistic regression model is a commonly used statistical method. It is estimated when the outcome variable follows a binomial distribution by using maximum likelihood methods. Coefficients of the final model are presented together with the respective odds ratio (OR) and a corresponding $95 \%$ confidence interval $(\mathrm{Cl})$.

Statistical analyses were performed with IBM Statistical Package for the Social Sciences version 18.0 software (IBM SPSS Corp.; Armonk, NY, USA). Data are presented as a mean (standard deviation) for continuous variables and as proportions for categorical variables.

\section{Results}

\section{Patient characteristics}

Clinical characteristics of the 185 patients are demonstrated in Table 1. The mean age of the patients was 39 years, and $76 \%$ were men. Overall, $116(71 \%)$ patients were pedestrians or motorcycle riders, and 170 (92\%) had a blunt injury. The mean transfer time was $39 \mathrm{~min}$. The survival rate was $86 \%$ (25/185). In either the prehospital or hospital setting, patients in the mortality group were not significantly older ( $p>0.05)$. The proportions of both groups also did not differ with respect to gender. The frequency of used resources in prehospital and hospital settings based on ESI method is illustrated in Figure 1.

\section{Survival analysis}

Univariate logistic regression analysis showed that used resources (calculated either by ESI or by the conventional method) is inversely associated with survival, which means that severely injured patients

Table 3. Multivariate analysis of variables according to the enter method (Ref=Survival)

\begin{tabular}{|l|c|c|c|c|c|c|c|c|}
\hline & & & & & & & \multicolumn{2}{|c|}{$95 \%$ C.I. } \\
\hline Variable & B & S.E. & Wald & df & Sig. & Exp (B) & Lower & Upper \\
\hline ESI-used resources in hospital & -0.727 & 0.185 & 15.45 & 1 & 0.000 & 0.483 & 0.336 & 0.694 \\
\hline Para-clinical resources in hospital & 1.379 & 0.443 & 9.688 & 1 & 0.002 & 3.972 & 1.667 & 9.468 \\
\hline ESI-used resources in prehospital & -0.655 & 0.317 & 4.259 & 1 & 0.039 & 0.519 & 0.279 & 0.968 \\
\hline Constant & 8.180 & 2.201 & 13.813 & 1 & 0.000 & 3570.004 & & \\
\hline
\end{tabular}

Table 4. Comparison of time measures between survival and mortality groups (min)

\begin{tabular}{|c|c|c|c|c|}
\hline Characteristics (minutes) & All & Survival & Mortality & $\mathbf{p}$ \\
\hline $\begin{array}{l}\text { Time to physician visit* } \\
\text { mean+/-SD }\end{array}$ & $\begin{array}{c}58.15 \pm 77.2 \\
(n=185)\end{array}$ & $\begin{array}{c}61.2 \pm 82.4 \\
(n=160)\end{array}$ & $\begin{array}{c}38.4 \pm 15.7 \\
(n=25)\end{array}$ & 0.171 \\
\hline $\begin{array}{l}\text { Time to intubation } \\
\text { mean+/-SD }\end{array}$ & $\begin{array}{c}93.97 \pm 107.1 \\
(n=60)\end{array}$ & $\begin{array}{c}107.6 \pm 122.9 \\
(n=38)\end{array}$ & $\begin{array}{c}70.3 \pm 68.5 \\
(n=22)\end{array}$ & 0.196 \\
\hline $\begin{array}{l}\text { Time to graphy } \\
\text { mean+/-SD }\end{array}$ & $\begin{array}{c}102.05 \pm 83.03 \\
(n=170)\end{array}$ & $\begin{array}{c}102.5 \pm 87.2 \\
(n=152)\end{array}$ & $\begin{array}{c}97.7 \pm 29.1 \\
(n=18)\end{array}$ & 0.816 \\
\hline $\begin{array}{l}\text { Time tolaboratory exam } \\
\text { mean+/-SD }\end{array}$ & $\begin{array}{c}150.0 \pm 117.5 \\
(n=175)\end{array}$ & $\begin{array}{l}155.1 \pm 122.1 \\
(n=156)\end{array}$ & $\begin{array}{c}107.8 \pm 53.5 \\
(n=19)\end{array}$ & 0.098 \\
\hline Time to sonography & $\begin{array}{c}63.9 \pm 45.1 \\
(n=60)\end{array}$ & $\begin{array}{c}65.4 \pm 46.9 \\
(n=54)\end{array}$ & $\begin{array}{c}50.5 \pm 21.3 \\
(n=6)\end{array}$ & 0.446 \\
\hline Time to CT scan & $\begin{array}{c}96.5 \pm 83.6 \\
(n=173)\end{array}$ & $\begin{array}{l}97.1 \pm 87.7 \\
(n=156)\end{array}$ & $\begin{array}{c}90.8 \pm 25.5 \\
(n=17)\end{array}$ & 0.769 \\
\hline
\end{tabular}


consumed more resources than other patients with TBI (Table 2). A multivariate logistic regression was performed to ascertain the effects of clinical parameters on the likelihood of survival of patients with TBI. The analysis showed that used resource is calculated based on ESI method either in prehospital or in hospital settings, and paraclinical resource predicts survival significantly. The model provided a statistically significant improvement over the constant-only model. The logistic regression model was statistically significant at $(X 2(2, n=185)=57.894$, $\mathrm{p}=0.0001$ ). The model explained the $86.5 \%$ variance in survival of patients with TBI. Nagelkerke $\mathrm{R}^{2}(49 \%)$ indicated a moderate relationship between prediction and grouping. The correct prediction rate was 91.4\% (98.1\% for survival and $48.0 \%$ for mortality). An enter logistic regression analysis showed that ESI-used resources in prehospital and hospital settings both inversely improved predictions $(p<0.05)$ (Table 3). Higher use of resources in prehospital and hospital settings predict a decrease in the probability of survival. In contrast, paraclinical resource consumption positively associated with survival. Alive patients often stay longer in ED than dead ones did; therefore, the probability of being tested increased. Survival group did not differ from mortality group in terms of time measures (Table 4).

\section{Discussion}

The result of this study showed that used resources based on the ESI method in patients with head trauma are valid, which means that prioritizing used resources based on the ESI method may have a significant association with mortality of patients with head trauma. ESI scale prediction is valid both in prehospital and hospital settings. It is also worth noting that this method provides a stronger validity than the conventional method (that takes a value of one for each resource) does. The more used resources increased, the less patients survived, as an increase in the used resources was associated with $48 \%$ decrease in survival probability in prehospital and $52 \%$ decrease in survival probability in the emergency room setting. This is because critically ill patients used more resources and had a higher mortality risk.

Used resources were calculated using two methods: conventional and ESI. In the conventional method, each used resource is assigned one value, whereas in the ESI scale, some of measures taken for the patients with trauma such as immobility or laboratory tests and radiographies are calculated once, no matter how many they are. Moreover, as some measures taken for patients with trauma such as immobility or several radiographies, CT scans, and sonographies are more frequent among patients with trauma, validity of the ESI scale in predicting the used resources could be significantly important with regard to the fact that no study has been conducted in this regard. Although in the regression model of the conventional method (whether in the prehospital or hospital settings), the relationship of the used resources with mortality was significant; in the multiple regression model, it was not significant and variables were not included in the final model. Of course, the only resources used in the paraclinical resources including laboratory tests and radiographies were significant because patients who survived could undergo more diagnostic tests in the emergency room. As a result, this variable was included in the final model. Therefore, receiving more diagnostic tests was associated with four times higher chance of survival comparing to those not receiving diagnostic tests. The underlying cause may be that a simple radiography or a blood test can be requested for patients with trauma even if they are not critically ill. This leads less critically ill patients to consume more resources. In contrast, radiography and tests may not be a priority for critically ill patients, and therefore, paraclinical resources did not increase for them. Elshove et al. (22) showed that performing a simple radiography is the most commonly used resource in category 4 and 5 patients.

We observed in the univariate regression model that a rise in used resources (except for laboratory tests), whether calculated using the conventional or the ESI method, indicated severity of the patient's illness and increased risk of mortality. ESI-used resources (ESI method) was significant in the multiple regression model. This means that the ESI method is valid to calculate resources in patients with trauma. Compared to clinical measures, radiographies and laboratory tests as resource have limited power to differ between critically ill patients and outpatients; therefore, counting several radiographies of the patients as one radiography or several laboratory tests as one test is enough to make a difference between critically ill patients and outpatients. However, clinical measures such as intravenous line, monitoring and other significantly increased scores, whereas patients with less severe illness receive fewer clinical measures. Table 3 suggests that patients who received more resources in prehospital setting or in the emergency room had decreased survival chances by $48 \%$ and $52 \%$, respectively. These findings are in line with the findings of other studies (23). Grossmann et al. (24) showed that mean resources used by patients with more severe illnesses (level 1) was significantly more than those used by patients with less severity (Level 1: 4.68, level 2: 3.17, level 3: 2.68, level 4: 1.08 and level 5: 0.32). Mortality in level 1 patients was equal to 27.3 . In another study, the mean of used resources used by level 1 patients was 7.48 (25). Mortality in level 1 patients was $58.6 \%$. As these studies suggest, the more frequent critically ill patients were, the more resources were also used. Although these two studies were conducted in general hospitals, the results of these studies indicated that this scale is also valid in patients with trauma. The mean of resources used by the mortality group in prehospital settings and the emergency room was 4.12 and 12 , respectively, which was significantly more than the mean in the survival group (2.85 and 10.31). Bigger number of resources used for critically ill patients compared to previous studies may be because patients with trauma need more intervention. Previous studies revealed that $85 \%$ of level 2 patients use more than two resources (22).

\section{Study limitations}

Our study was limited to one hospital trauma center in a densely populated area of a metropolitan city. We could not extend the study period further because strict supervision was required to collect reliable data. Therefore, other studies may want to replicate this study with larger sample sizes. Other limitation of this study was the fact that the paramedics collected data in the field, and we used the documented data in the ED. Paramedics were well trained and educated, so documented data can be considered reliable.

\section{Conclusion}

The ESI triage system is valid to calculate used resources among patients with trauma. ESI has greater power to predict mortality based on used resources than the conventional method because radiographies and laboratory tests are calculated once. Therefore, the ESIused resource protocol may be used to predict mortality in patients with trauma. 
Ethics Committee Approval: Ethics committee approval was received for this study from the Ethics Committee of Mashhad University of Medical Sciences (Approval Number: 940948).

Informed Consent: The study is granted exemption from ethics committee, so informed consent is not required because the study involves no more than minimal risk to the subjects.

Peer-review: Externally peer-reviewed.

Author Contributions: Concept - A.M.; Design - Z.N., H.Z., A.M.; Supervision Z.N., H.Z., A.M.; Resources - A.M., M.E., A.A.; Data Collection and/or Processing - Z.N., H.Z., A.M.; Analysis and/or Interpretation - Z.N., H.Z., A.A., M.E. and A.M.; Literature Search - Z.N., H.Z., A.M.; Writing Manuscript - Z.N., H.Z., A.M.; Critical Review - Z.N., H.Z., A.A., M.E. and A.M Other - M.E., A.A.

Acknowledgements: We would like to thank personnel of the Hasheminezhad hospital for the cooperation during study period.

Conflict of Interest: The authors have no conflict of interest to declare.

Financial Disclosure: The authors declared that this study has received grant from the Vice Chancellor of Research of Mashhad University of Medical Sciences.

\section{References}

1. Karakus A, Kekec Z, Akcan R, Seydaoglu G. The relationship of trauma severity and mortality with cardiac enzymes and cytokines at multiple trauma patients. Ulus Travma Acil Cerrahi Derg. 2012; 18: 289-95. [CrossRef]

2. Salehi O, Dezfuli SAT, Namazi SS, Khalili MD, Saeedi M. A new injury severity score for predicting the length of hospital stay in multiple trauma patients. Trauma Mon. 2016; 21: e20349. [CrossRef]

3. Montoya KF, Charry JD, Calle-Toro JS, Núñez LR, Poveda G. Shock index as a mortality predictor in patients with acute polytrauma. J Acute Dis. 2015; 4: 202-4. [CrossRef]

4. Harmsen AMK, Giannakopoulos GF, Moerbeek PR, Jansma EP, Bonjer HJ, Bloemers FW. The influence of prehospital time on trauma patients outcome: a systematic review. Injury. 2015; 46: 602-9. [CrossRef]

5. Rotondo M, Cribari C, Smith R, Trauma ACoSCo. Resources for optimal care of the injured patient. J Am Coll Surg. 2014; 6 .

6. Mackersie RC. History of trauma field triage development and the american college of surgeons criteria. Prehosp Emerg Care. 2006; 10: 287-94. [CrossRef]

7. Esposito TJ, Maier RV, Rivara FP, Pilcher S, Griffith J, Lazear S, et al. The impact of variation in trauma care times: urban versus rural. Prehosp Disaster Med. 1995; 10: 161-6. [CrossRef]

8. Grossman DC, Kim A, Macdonald SC, Klein P, Copass MK, Maier RV. Urban-rural differences in prehospital care of major trauma. J Trauma Acute Care Surg. 1997; 42: 723-9. [CrossRef]

9. Dharap S, Kamath S, Kumar V. Does prehospital time affect survival of major trauma patients where there is no prehospital care? J Postgrad Med. 2017; 63: 169-75. [CrossRef]
10. Desmettre T, Yeguiayan J-M, Coadou H, Jacquot C, Raux M, Vivien B, et al. Impact of emergency medical helicopter transport directly to a university hospital trauma center on mortality of severe blunt trauma patients until discharge. Crit Care. 2012; 16: R170. [CrossRef]

11. Alarhayem A, Myers J, Dent D, Liao L, Muir M, Mueller D, et al. Time is the enemy: mortality in trauma patients with hemorrhage from torso injury occurs long before the "golden hour". Am J Surg. 2016; 212: 1101-5. [CrossRef]

12. Thelin EP, Nelson DW, Vehviläinen J, Nyström H, Kivisaari R, Siironen J, et al. Evaluation of novel computerized tomography scoring systems in human traumatic brain injury: An observational, multicenter study. PLoS Med. 2017; 14: e1002368. [CrossRef]

13. Allen $\mathrm{CJ}$, Tashiro J, Valle EJ, Thorson CM, Shariatmadar S, Schulman Cl, et al. Initial hematocrit predicts the use of blood transfusion in the pediatric trauma patient. J Pediatr Surg. 2014; 49: 1678-82. [CrossRef]

14. Rossaint R, Bouillon B, Cerny V, Coats TJ, Duranteau J, Fernández-Mondéjar $E$, et al. The European guideline on management of major bleeding and coagulopathy following trauma. Crit Care. 2016; 20: 100. [CrossRef]

15. Thorson CM, Van Haren RM, Ryan ML, Pereira R, Olloqui J, Guarch GA, et al. Admission hematocrit and transfusion requirements after trauma. J Am Coll Surg. 2013; 216: 65-73. [CrossRef]

16. Mirhaghi A, Mazlom R, Heydari A, Ebrahimi M. The reliability of the Manchester Triage System (MTS): a meta-analysis. J Evid Based Med. 2017; 10: 129-35. [CrossRef]

17. Mirhaghi A. Triage system should be compatible with culture of care in emergency department. Med Klin Intensivmed Notfmed. 2016; 111:1389. [CrossRef]

18. Tanabe P, Gimbel R, Yarnold PR, Kyriacou DN, Adams JG. Reliability and validity of scores on The Emergency Severity Index version 3. Acad Emerg Med. 2004; 11: 59-65. [CrossRef]

19. Najafi Z, Zakeri H, Mirhaghi A. The accuracy of acuity scoring tools to predict 24-h mortality in traumatic brain injury patients: A guide to triage criteria. Int Emerg Nurs. 2018; 36: 27-33. [CrossRef]

20. Tanabe P, Gimbel R, Yarnold PR, Adams JG. The Emergency Severity Index (version 3) 5-level triage system scores predict ED resource consumption. J Emerg Nurs. 2004; 30: 22-9. [CrossRef]

21. Wuerz RC, Milne LW, Eitel DR, Travers D, Gilboy N. Reliability and validity of a new five-level triage instrument. Acad Emerg Med. 2000; 7: 236-42. [CrossRef]

22. Elshove-Bolk J, Mencl F, van Rijswijck B, Weiss E, Simons M, van Vugt A. Dutch emergency department patient characteristics: implications for an emergency medicine residency program. J Emerg Med. 2006; 30: 2378. [CrossRef]

23. Wuerz R. Emergency severity index triage category is associated with six-month survival. ESI Triage Study Group. Acad Emerg Med. 2001; 8: 61-4. [CrossRef]

24. Grossmann FF, Nickel $\mathrm{CH}$, Christ $\mathrm{M}$, Schneider $\mathrm{K}$, Spirig R, Bingisser R. Transporting clinical tools to new settings: cultural adaptation and validation of the Emergency Severity Index in German. Ann Emerg Med. 2011; 57: 257-64. [CrossRef]

25. Baumann MR, Strout TD. Triage of geriatric patients in the emergency department: validity and survival with the Emergency Severity Index. Ann Emerg Med. 2007; 49: 234-40. [CrossRef] 